\title{
Physical Quantity to Physical Quantity Time Ratio Data Type
}

National Cancer Institute

\section{Source}

National Cancer Institute. Physical Quantity to Physical Quantity Time Ratio Data Type. NCI Thesaurus. Code C95677.

A data type comprised of a physical quantity divided by a physical quantity expressed in units of time. 